\title{
Ultrasonography Detected Missed Lunate Volar Dislocation Associated With Median Neuropathy: A Case Report
}

\author{
Kyeongwon Kim, MD, Min-Wook Kim, MD, PhD \\ Department of Rehabilitation Medicine, Incheon St. Mary's Hospital, College of Medicine, \\ The Catholic University of Korea, Incheon, Korea
}

\begin{abstract}
Lunate and perilunate dislocations are uncommon, but they have clinical importance because complications, such as median neuropathy and avascular necrosis of the lunate, can occur. Although early diagnosis enabling early surgical treatment is crucial for preventing long-term sequelae, these dislocations are frequently missed in the initial assessment. Imaging tools, such as plain radiography, magnetic resonance imaging, ultrasonography, and electrodiagnostic studies, have been used for diagnosis. The proper choice of initial evaluation tools is important for making an accurate early diagnosis. Here we present a case of lunate dislocation associated with median neuropathy in which ultrasonography, along with the electrodiagnostic study and plain radiography, played an important diagnostic role in detecting structural abnormalities. This case report reveals the complementary diagnostic role of ultrasonography in initial assessment and provides ultrasonographic images of lunate dislocation as a cause of median neuropathy.
\end{abstract}

Keywords Dislocation, Lunate bone, Ultrasonography

\section{INTRODUCTION}

Lunate and perilunate dislocations are uncommon, accounting for $<10 \%$ of wrist injuries [1]. A misaligned lunar or perilunar carpal bone can be a hidden cause of carpal tunnel syndrome resulting from the narrowing of the carpal tunnel and compression of the median nerve. However, lunate/perilunate dislocation associated with median neuropathy is often missed at initial evaluation
[2]. Adequate initial imaging tools, including plain radiography and ultrasonography, are crucial for the early diagnosis of underlying structural causes that may require surgical management. Here we present a case of lunate dislocation associated with median neuropathy in which ultrasonography played an important role in initial diagnosis and provide representative ultrasonographic images of lunate dislocation as a cause of median neuropathy.

Received August 12, 2016; Accepted October 10, 2016

Corresponding author: Min-Wook Kim

Department of Rehabilitation Medicine, Incheon St. Mary's Hospital, College of Medicine, The Catholic University of Korea, 56 Dongsu-ro, Bupyeonggu, Incheon 21431, Korea. Tel: +82-32-280-5981, Fax: +82-32-280-5992, E-mail: minukkim@nate.com

ORCID: Kyeongwon Kim (https://orcid.org/0000-0001-6185-0058); Min-Wook Kim (https://orcid.org/0000-0003-4505-809X).

@ This is an open-access article distributed under the terms of the Creative Commons Attribution Non-Commercial License (http://creativecommons.org/ licenses/by-nc/4.0) which permits unrestricted noncommercial use, distribution, and reproduction in any medium, provided the original work is properly cited. Copyright $\odot 2017$ by Korean Academy of Rehabilitation Medicine 


\section{CASE REPORT}

A 68-year-old man with a medical history of hypertension, dyslipidemia, and stroke was referred for electrodiagnostic study due to right palm paresthesia and thenar weakness 3 weeks after falling down the stairs. As his initial chief complaint was a deep right periorbital laceration, dizziness, and right-palm paresthesia, he was admitted to the Department of Neurosurgery to rule out a brain lesion and underwent a brain MRI, which revealed no newly developed abnormality. Subsequently, he was referred to the Department of Rehabilitation Medicine to determine the underlying cause of right-hand paresthesia. Upon physical examination, there was a numbness and tingling sensation along a right median nerve distribution and right thumb abduction weakness (grade 4/5). Phalen's sign was positive on the right side. Tinel's sign was positive when percussion was performed on the right wrist, specifically slightly distal to the wrist crease, where proximal carpal bones were located. Edema or tenderness around the wrist was not evident.

On a nerve conduction study, the sensory nerve potential of the right median nerve, stimulated at the wrist and palm, and recorded on the second, third, and fourth fingers, was absent (Table 1). The compound motor action potential of the right median nerve, stimulated at the wrist and recorded on the abductor pollicis brevis mus- cle, was also absent. A needle electromyography (EMG) showed abnormal spontaneous activity at rest, reduced recruitment of motor unit action potentials on minimal volition, and discrete interference of motor unit action potentials on maximal volition in the right abductor pollicis brevis muscle. These electrodiagnostic findings suggested a severe axonal injury in right median nerve at the wrist.

To determine possible structural abnormalities, an ultrasonography was performed. It revealed volar dislocation of the lunate bone that compressed the median nerve in the carpal tunnel. Proximal to the compression site, the median nerve was swollen (cross-sectional area, $0.119 \mathrm{~cm}^{2}$ ). Only the median nerve and one flexor tendon were observed over the lunate bone (Fig. 1A, 1B). Ultrasonography of a normal, similarly-aged man for comparison showed a normal alignment of the carpal bones and a non-compressed median nerve (Fig. 1C, 1D). The patient's plain radiographs showed volar dislocation of the lunate bone and an ulnar styloid process fracture (Fig. 2A, 2B). The plain radiographs were compared with those of the patient's other hand, which showed a normal alignment of the carpal bones (Fig. 2C, 2D). A wrist MRI provided additional information, revealing flexor synovitis and bone contusion in the carpal bone and distal radius (Fig. 3A, 3B).

Open reduction of the lunate bone and repair of the

Table 1. Results of nerve conduction study performed initial (3 weeks after onset) and follow-up (4 years after onset) assessment

\begin{tabular}{|c|c|c|c|c|c|c|c|c|}
\hline & \multicolumn{5}{|c|}{ Nerve conduction study } & \multicolumn{3}{|c|}{ Needle EMG } \\
\hline & $\begin{array}{l}\text { DSL } \\
(\mathrm{ms})\end{array}$ & $\begin{array}{c}\text { S Amp } \\
(\mu \mathrm{V})\end{array}$ & $\begin{array}{l}\text { DML } \\
\text { (ms) }\end{array}$ & $\begin{array}{c}\text { M Amp } \\
(\mathrm{mV})\end{array}$ & $\begin{array}{l}\text { NCV } \\
(\mathrm{m} / \mathrm{s})\end{array}$ & $\begin{array}{l}\text { Resting } \\
\text { activity }\end{array}$ & $\begin{array}{c}\text { Recruit- } \\
\text { ment }\end{array}$ & $\begin{array}{c}\text { Interfer- } \\
\text { ence }\end{array}$ \\
\hline \multicolumn{9}{|c|}{ Initial study (3 weeks after onset) } \\
\hline \multicolumn{9}{|l|}{ Rt. median nerve } \\
\hline Stimulated at wrist & $\mathrm{NE}$ & NE & NE & $\mathrm{NE}$ & $\mathrm{NE}$ & & & \\
\hline Stimulated at palm & NE & NE & - & - & - & & & \\
\hline Rt. APB & & & & & & 1 Fib, 3 PSW & Reduced & Discrete \\
\hline \multicolumn{9}{|c|}{ F/U study (4 years after onset) } \\
\hline \multicolumn{9}{|l|}{ Rt. median nerve } \\
\hline Stimulated at wrist & 4.10 & 17.1 & 3.80 & 7.9 & 56.8 & & & \\
\hline Stimulated at palm & 1.85 & 24.3 & - & - & - & & & \\
\hline Rt. APB & & & & & & $\mathrm{N}$ & $\mathrm{N}$ & $\mathrm{N}$ \\
\hline
\end{tabular}

EMG, electromyography; DSL, distal sensory latency; S Amp, sensory amplitude; DML, distal motor latency; M Amp, motor amplitude; NCV, nerve conduction velocity; NE, not evoked; APB, abductor pollicis brevis; Fib, fibrillation potential; PSW, positive sharp wave; F/U, follow-up; N, normal. 

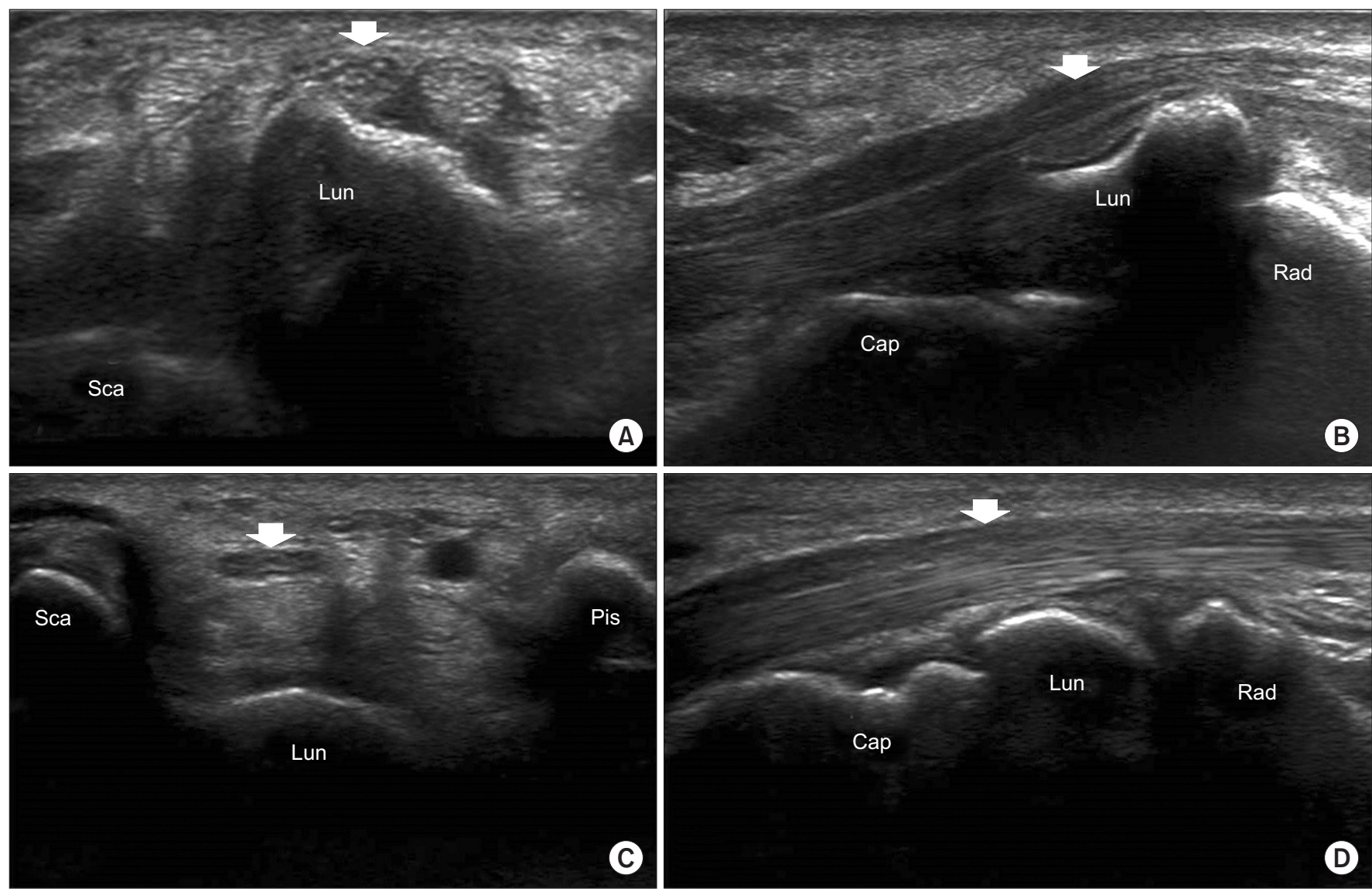

Fig. 1. Wrist ultrasound images of the patient (A, B) and a normal subject (C, D). (A) A transverse 12-5 MHz ultrasound image of the patient demonstrates the median nerve and only one flexor tendon over the dislocated lunate bone. (B) A longitudinal ultrasound image of the patient clearly shows volar dislocation of the lunate bone. (C, D) Ultrasound images of a normal subject show a normal alignment of the carpal bones and a non-compressed median nerve. (C) Transverse view. (D) Longitudinal view. Sca, scaphoid; Lun, lunate; Pis, pisiform; Cap, capitate; Rad, radius; white arrow, median nerve.

scapholunate, lunotriquetral, and radiolunate ligaments were performed by the dorsal approach. A carpal tunnel release or median neurorrhaphy was not performed. One year later, the patient's sensory disturbance and thumb weakness were improved, consistent with the follow-up ultrasonography and plain radiography findings, revealing a repositioned lunate bone and non-compressed median nerve (Fig. 4). A follow-up electrodiagnostic study was performed 4 years later (Table 1). The sensory nerve conduction study demonstrated slowed conduction of the right median nerve across the carpal tunnel region. A needle EMG showed no abnormal spontaneous activities at rest, normal recruitment, and interferential patterns on volition in the right abductor pollicis brevis muscle.

\section{DISCUSSION}

Perilunate and lunate dislocations are injuries on the spectrum of carpal dislocations and fracture-dislocations [3]. They usually occur after high-energy hyperextension wrist injuries. Perilunate dislocation refers to the condition that carpal bones are displaced dorsally to the lunate bone. Lunate dislocation, which refers to the displacement of the lunate bone from lunate fossa of the distal radius, is a later stage of the perilunate dislocation.

Previous reports described cases of perilunate and lunate dislocations that were initially missed and diagnosed later [1,2,4-6]. About $25 \%$ of perilunate dislocations were reportedly missed on initial presentation and only $61 \%$ of cases were treated within the first week [1]. However, delayed diagnosis of perilunate or lunate dislo- 

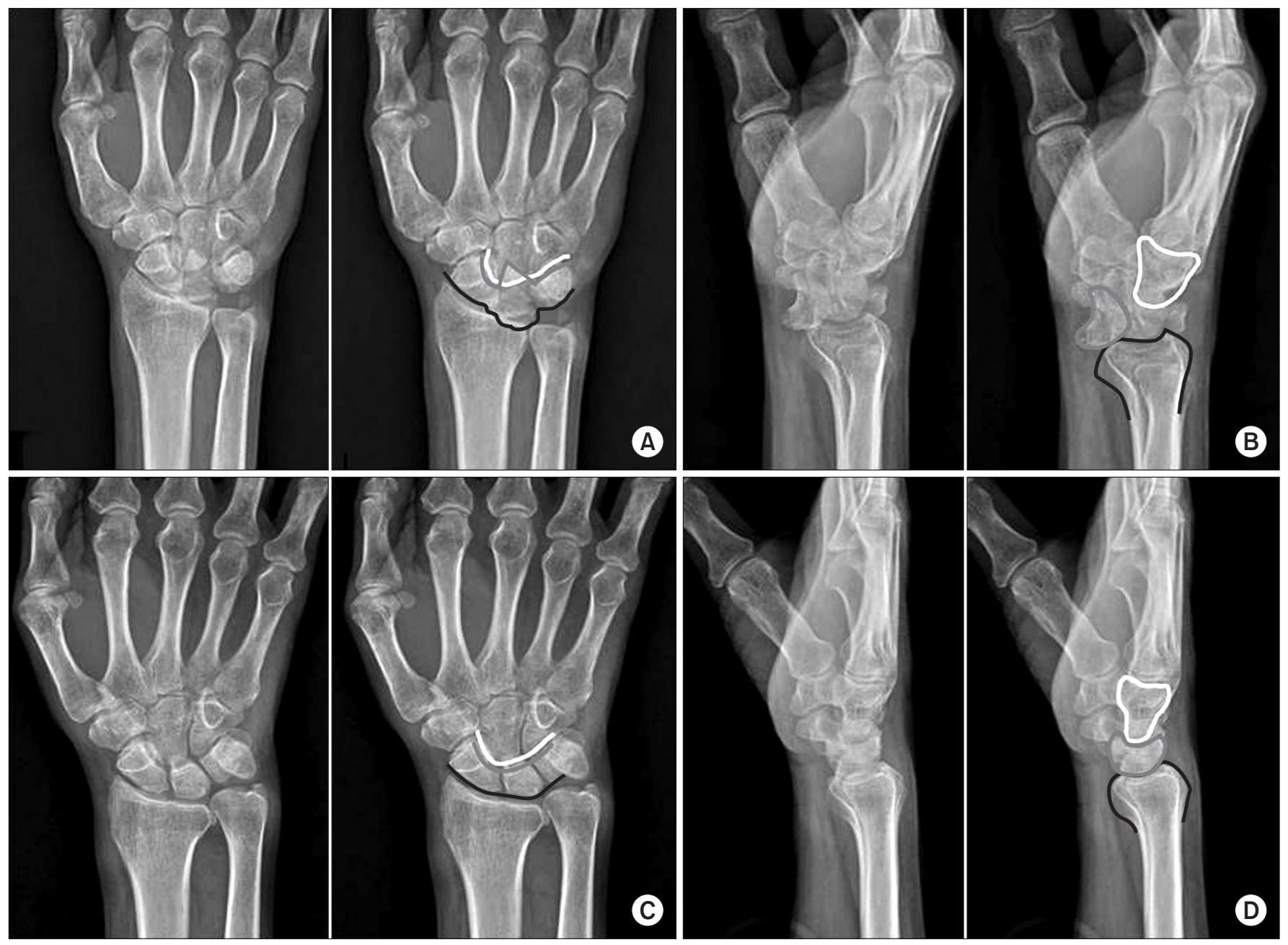

Fig. 2. Plain wrist radiographs of the patient on the symptomatic side (A, B) and the asymptomatic side (C, D). (A) The anterior-posterior view shows a triangular or wedge-shaped lunate bone and a styloid process fracture. In the right image, the 'arcs of Gilula', representing the carpal row borders, are illustrated. The black line marks the proximal margin of the proximal carpal row (scaphoid, lunate, and triquetrum). The gray line marks the distal margin of the same three bones. The white line marks the proximal margin of the hamate and capitate bones. The arcs of Gilula are obviously disrupted. (B) The lateral radiograph shows loss of lunate (gray line) and radius bone (black line) collinearity, with the lunate bone tilted volarly and dislocated (the 'spilled teacup' sign). The capitate bone is outlined in white. (C, D) Plain anterior-posterior and lateral radiographs of the asymptomatic side show normal arcs of Gilula and alignment of radius, lunate, and capitate bones. The images in (C) and (D) are flipped over the right to the left.
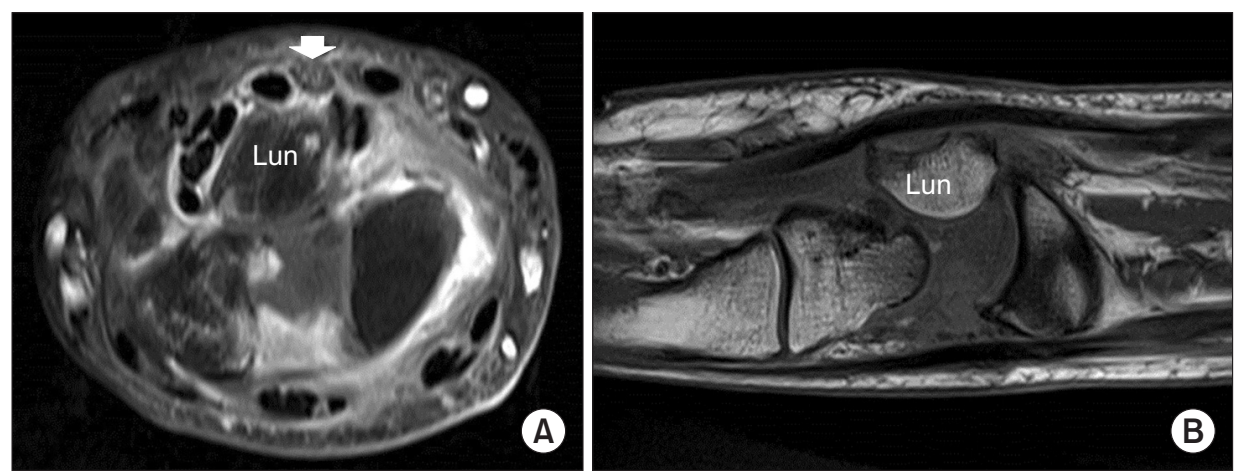

Fig. 3. Contrast-enhanced magnetic resonance imaging $(A$, transverse; $B$, coronal) additionally shows flexor tendon synovitis. 

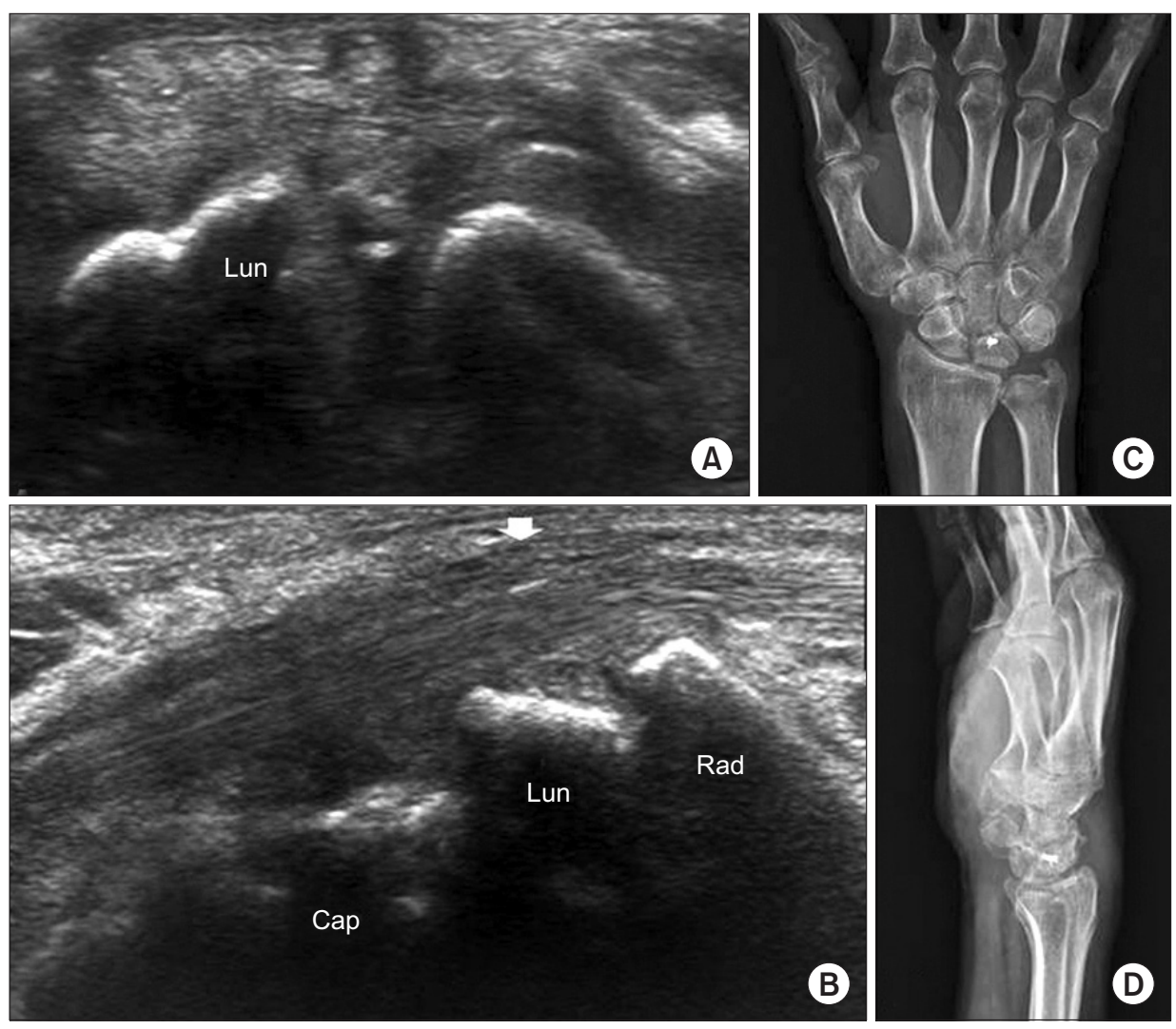

B

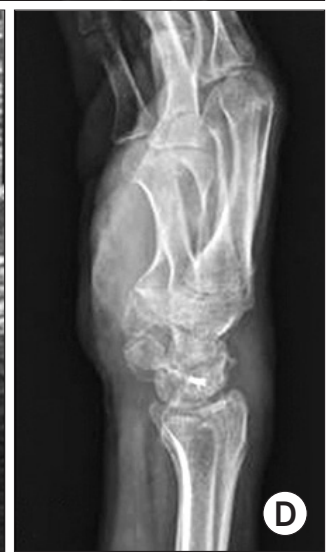

Fig. 4. Ultrasound images (A, transverse; $\mathrm{B}$, longitudinal) and plain radiographs $(\mathrm{C}$, anteriorposterior; D, lateral) at the wrist 1 -year post-operation show good carpal bone alignment and a noncompressed median nerve (white arrow). cation can lead to late complications, including median neuropathy, avascular necrosis, and osteoarthritis of the carpal bone. The reported rate of median nerve injury by lunate dislocation ranges from $24 \%-45 \%$ [7].

The typical treatment of median neuropathy associated with perilunate or lunate dislocation is surgical management. As the median nerve is positioned adjacent to the lunate and capitate bones, open reduction of the dislocated lunate and repair of the carpal ligaments, including the scapholunate ligament, should be performed. In previously reported cases, transverse carpal ligament release alone after overlooking lunate dislocation as a cause of carpal tunnel syndrome failed to relieve symptoms and resulted in relapse $[2,6]$.

Initial diagnosis of lunate and perilunate dislocations has usually been made by plain radiography. Ensuring the continuity of the 'arcs of Gilula' on anterior-posterior radiographs and normal collinearity of the distal radius, lunate, capitate, and metacarpal base of the middle finger on lateral radiographs is the most widely-used method for determining abnormalities in a carpal alignment as illustrated in Fig. 2 [8-10]. Although plain radiography has superiority for generally assessing carpal alignment, it cannot assess soft tissue structures, including nerves and tendons. Moreover, without careful attention to carpal alignment, carpal dislocations are frequently missed. In contrast, ultrasonography, as shown in our case, accurately identified lunate dislocation, the proximity of the median nerve, and the dislocated lunate bone, and morphologic changes in the median nerve, such as compression and enlargement. Our case showed that ultrasonography can play an important complementary role in revealing the underlying cause of neuropathy such as space-occupying lesions. Ultrasonography is easily applicable for initial evaluation due to its portability, low cost, short examination time, and wide availability in contrast to MRI. Moreover, carpal instability can be assessed by an ultrasonographic dynamic stress test.

In this case, ultrasonographic imaging played an important diagnostic role in identifying lunate dislocation associated with median neuropathy. We recommend ultrasonography along with an electrodiagnostic study for initially assessing patients suspected to have median neuropathy, especially after traumatic injury at the wrist level, because ultrasonography can reveal the underlying structural cause of median neuropathy. 


\section{CONFLICT OF INTEREST}

No potential conflict of interest relevant to this article was reported.

\section{REFERENCES}

1. Youssef B, Deshmukh SC. Volar perilunate dislocation: a case report and review of the literature. Open Orthop J 2008;2:57-8.

2. Ott F, Mattiassich G, Kaulfersch C, Ortmaier R. Initially unrecognised lunate dislocation as a cause of carpal tunnel syndrome. BMJ Case Rep 2013;2013.

3. Mayfield JK, Johnson RP, Kilcoyne RK. Carpal dislocations: pathomechanics and progressive perilunar instability. J Hand Surg Am 1980;5:226-41.

4. Cara J, Narvaez A, de la Varga V, Guerado E. Median nerve neuropathy from an old lunate dislocation. Acta
Orthop Belg 1998;64:100-3.

5. Sochart DH, Birdsall PD, Paul AS. Perilunate fracturedislocation: a continually missed injury. J Accid Emerg Med 1996;13:213-6.

6. Chen WS. Median-nerve neuropathy associated with chronic anterior dislocation of the lunate. J Bone Joint Surg Am 1995;77:1853-7.

7. Stanbury SJ, Elfar JC. Perilunate dislocation and perilunate fracture-dislocation. J Am Acad Orthop Surg 2011;19:554-62.

8. Peh WC, Gilula LA. Normal disruption of carpal arcs. J Hand Surg Am 1996;21:561-6.

9. Scalcione LR, Gimber LH, Ho AM, Johnston SS, Sheppard JE, Taljanovic MS. Spectrum of carpal dislocations and fracture-dislocations: imaging and management. AJR Am J Roentgenol 2014;203:541-50.

10. Navaratnam AV, Ball S, Emerson C, Eckersley R. Perilunate dislocation. BMJ 2012;345:e7026. 